\title{
UNCERTAINTY AND THE DESIGN OF LONG-RUN FISCAL POLICY
}

\author{
Alan J. Auerbach \\ Kevin A. Hassett \\ Working Paper 7036 \\ http://www.nber.org/papers/w7036
}

\section{NATIONAL BUREAU OF ECONOMIC RESEARCH \\ 1050 Massachusetts Avenue \\ Cambridge, MA 02138 \\ March 1999}

This paper was prepared for a conference on Demographic Change and Fiscal Policy, held in Berkeley, October 16-17, 1998. We are grateful to our discussants, Peter Diamond and Shripad Tuljapurkur, and other conference participants for helpful comments on an earlier draft. The views expressed in this paper are those of the authors and do not reflect those of the National Bureau of Economic Research.

(C) 1999 by Alan J. Auerbach and Kevin A. Hassett. All rights reserved. Short sections of text, not to exceed two paragraphs, may be quoted without explicit permission provided that full credit, including $\mathbb{C}$ notice, is given to the source. 
Uncertainty and the Design of Long-Run Fiscal Policy

Alan J. Auerbach and Kevin A. Hassett

NBER Working Paper No. 7036

March 1999

JEL No. E62, H62

\section{ABSTRACT}

This paper explores optimal fiscal policy in an overlapping-generations general-equilibrium model under uncertainty, and the impact on optimal policy of the introduction of a type of policy stickiness intended to account for the stylized fact that major reforms happen infrequently.

In general, our analysis suggests not only that action should not be delayed, but further that action should actually be accelerated. The added realism of restrictions on the frequency of policy changes alters this result in two ways. The prospect of being unable to set policy in the future occasions even more precautionary saving today, if the government acts. However, the government may also choose not to set policy, and its inaction range is very asymmetric. Because the impact of its policies on the current elderly cannot be reversed in the future, the government is much more likely to choose inaction when fiscal tightening is called for. Thus, the optimal policy response over time might best be characterized by great caution in general, but punctuated by occasional periods of apparent irresponsibility.
Alan J. Auerbach
Department of Economics
University of California
Berkeley, CA 94720-3880
and NBER
auerbach@econ.berkeley.edu

Kevin A. Hassett

AEI

1150 Seventeenth St. N.W.

Washington, DC 20036-4670

khassett@aei.org 


\section{Introduction}

Over time, the share of federal government expenditures tied to age-related programs, particularly those focusing on the elderly, has grown rapidly. For example, U.S. spending on Social Security (OASDI) and Medicare alone has risen from 15 percent of the federal budget in fiscal year 1966 (the year of Medicare's introduction) to 35 percent in fiscal year 1998, and is projected to grow to 44 percent of the federal budget during the next decade (Congressional Budget Office 1998). Combined with the changing composition of the U.S. population, this change in spending composition has led to serious questions about the viability of current fiscal policy, both in the United States and abroad (e.g., Auerbach et al 1999).

Dealing with the apparent fiscal imbalances associated with aging populations raises difficult questions about how and when to change policy. Projected long-term cash-flow imbalances are so large that significant immediate adjustments appear necessary to avert serious economic problems. However, with considerable uncertainty about how serious future cash-flow imbalances will be, there is also a natural tendency to put off dealing with problems that might not materialize. This tendency is magnified by the perception that old-age transfer programs, particularly Social Security, are a "third rail" of American politics, and a sense that a change today may make it harder to alter the system tomorrow. As a result, policy changes have been relatively infrequent, suggesting that a key feature of the current system is that it does not allow policy makers to adjust taxes and transfers very frequently, that is, Social Security policy is "sticky".

The fundamental question addressed in this paper is how and when to deal with long-term fiscal imbalances that are at once very significant and very uncertain, given that political constraints may make frequent changes to the system impossible. Unlike much current 
discussion that focuses on the institutional features of specific reforms, such as whether to scale back and/or privatize the Social Security system, our approach is to use simpler and more stylized models in search of more general conclusions regarding the nature of optimal policy responses. We consider policy under different assumptions regarding the flexibility of government decisions. To account for the various types of important economic shocks, we consider three sources of uncertainty: depreciation (which affects the productivity of capital), technological progress (which affects the productivity of both capital and labor), and life span, which affects the consumption needs of different generations.

We proceed in two steps. First, we explore the impact of uncertainty on optimal policy when policy is free to change each period. Second, we construct a simulation model to help us examine the impact of policy stickiness on social welfare and the choice of optimal policy.

\section{Government Policy in an Overlapping Generations Model}

Throughout the paper, we analyze policy design using the familiar two-period overlapping-generations model. For the sake of simplicity, we assume that there are no bequests, no heterogeneity within each generation, and no capital market imperfections. Thus, we abstract from many of the important issues that arise, for example, in discussions of optimal social security design, because we wish to focus on issues of timing and intergenerational redistribution.

Consider an economy in which each generation lives for two periods. There are three sources of uncertainty: general productivity, the rate of capital depreciation, and life span, as represented by the length of life during the second period. Each generation has a single, representative individual. 
Initially, we assume that production and preferences are Cobb-Douglas. Production of output obeys the expression:

$$
Y_{t}=K_{t}^{\alpha} A_{t}^{1-\alpha}
$$

where $A_{t}$ is the level of labor productivity at date $t$. In efficiency units, the wage rate at $t$ is:

$$
w_{t}=(1-\alpha)\left(\frac{K_{t}}{A_{t}}\right)^{\alpha}
$$

while the gross return to capital is:

$$
r_{t}=\alpha\left(\frac{K_{t}}{A_{t}}\right)^{\alpha-1}
$$

Preferences obey:

$$
U_{t}=\ln C_{1 t}+E_{t} \beta_{t+1} \ln \left(\frac{C_{2 t+1}}{\beta_{t+1}}\right)
$$

where $U_{t}$ is the expected utility of the generation born in period $t, C_{1 t}\left(C_{2 t}\right)$ is the consumption of the younger (older) generation in period $t$, and $\beta_{t}$ is the length of second-period life for the older generation in period $t$. The form of second period utility is based on the notion that the period is really divided into $\beta$ sub-periods, each with equal weight and consumption.

Consider first the economy's equilibrium without government. Utility maximization (which with homothetic preferences can be considered in terms of efficiency units) yields the expression for first-period consumption: 


$$
C_{1 t}=\frac{w_{t}}{1+E_{t} \beta_{t+1}}
$$

Letting $\delta_{t}$ be the rate of capital depreciation at date $t$, we know that:

$$
C_{2 t}=K_{t}\left(1+r_{t}-\delta_{t}\right)
$$

Thus, with use made of (1), (2), (3), (5) and (6), the capital transition equation is:

$$
K_{t+1}=Y_{t}+\left(1-\delta_{t}\right) K_{t}-C_{1 t} A_{t}-C_{2 t}=K_{t}^{\alpha} A_{t}^{1-\alpha}(1-\alpha)\left(1-\frac{1}{1+E_{t} \beta_{t+1}}\right)
$$

This provides a complete solution for the economy's evolution with no government. Now, consider the impact of having safe government debt, $B_{t}$, and taxes on each generation, $T_{1 t}$ and $T_{2 t}$, such that:

$$
B_{t+1}=\left(1+v_{t}\right) B_{t}-T_{1 t} A_{t}-T_{2 t}
$$

where $v_{t}$ is the market-determined safe rate of return.

There are various possible interpretations of the terms $T_{1 t}$ and $T_{2 t}$. One may think of them as representing the tax and benefit components, respectively, of a public pension scheme. However, for convenience, we assume that the second-period tax, $T_{2 t}$, is imposed as a proportional tax on second-period capital income. Although this appears to impose a distortion, the government's optimal policy will turn out to be one that eschews distortionary taxation.

Letting $\theta_{t}$ be the amount of savings put into government bonds in period $t$, we may write the household's optimization problem at time $t$ as: 


$$
\max _{C_{1 t}, \theta_{t}} \ln C_{1 t}+E_{t+1} \beta_{t+1} \ln \left[\frac{\left(W_{t}-T_{1 t}-C_{1 t}-\theta_{t}\right)\left(1+r_{t+1}^{n}-\delta\right)+\theta_{t}\left(1+v_{t+1}^{n}\right)}{\beta_{t+1}}\right]
$$

where the superscript $n$ signifies an after-tax return. The household now chooses how much to invest in government bonds, $\theta$, as well as how much to consume in the first period, $C_{1}$.

Combining the two first-order conditions corresponding to these choices yields:

$$
C_{1 t}=\frac{W_{t}-T_{1 t}}{1+E_{t} \beta_{t+1}}
$$

which corresponds to (5) for the no-government case. The expression for second-period consumption corresponding to (6) is:

$$
C_{2 t}=K_{t}\left(1+r_{t}-\delta_{t}\right)+B_{t}\left(1+v_{t}\right)-T_{2 t}=K_{t}\left(1+r_{t}-\delta_{t}\right)+B_{t+1}+T_{1 t} A_{t}
$$

where the last substitution follows from (8). Substituting (10) and (11) into the first line of (7) yields the modified transition equation for capital:

$$
K_{t+1}=K_{t}^{\alpha} A_{t}^{1-\alpha}(1-\alpha)\left(1-\frac{1}{1+E_{t} \beta_{t+1}}\right)-T_{1 t} A_{t}\left(1-\frac{1}{1+E_{t} \beta_{t+1}}\right)-B_{t+1}
$$

\section{Optimal Policy without Constraints}

We are now in a position to maximize social welfare through the choice of $\left\{T_{t}, B_{t+1}\right\}$ at date $t$, subject to expectations at date $t$. We assume an additively separable social welfare function with weight $\omega_{t}$ assigned to generation $t$. Our objective, therefore, is to maximize ${ }^{1}$

$$
V_{t}=\omega_{t-1} \beta_{t} \ln C_{2 t}+\omega_{t} \ln \left(C_{1 t} A_{t}\right)+E_{t} V_{t+1}
$$


subject to the transition equation in (12). To do so, we form the Hamiltonian with costate variable $\lambda_{t}$ associated with (12).

Note that for the government's problem of maximizing (13), based on (10) and (11) and subject to the resource constraint described in (12), the initial stock of government debt, $B_{t}$ is absent: the stock of debt is irrelevant to the optimal solution. This makes sense, because national debt is simply an accounting construct in this model (see, e.g., Auerbach and Kotlikoff 1987, for further elaboration). It is possible to increase the initial stock of debt and reduce the transfers to the elderly in the initial period of optimization without affecting the welfare of the young or the old or the opportunity set available for the future. This shift would occur, for example, if we relabeled some of the taxes and transfers of a social security system as purchases of debt and payments of interest and principal on that debt.

After some algebra, the first-order conditions with respect to $T_{1 t}, B_{t+1}$, and $K_{t}$ yield the following expressions for the optimal values of $C_{1 t}$ and $C_{2 t}$ and the optimal evolution of $\lambda_{t}$ :

$$
\begin{aligned}
& C_{1 t} A_{t}=\frac{\omega_{t}}{\lambda_{t}} ; \quad \text { (b) } C_{2 t}=\frac{\omega_{t-1} \beta_{t}}{\lambda_{t}} \\
& \lambda_{t-1}=E_{t-1}\left[\lambda_{t}\left(1+r_{t}-\delta_{t}\right)\right]
\end{aligned}
$$

These conditions would also follow if we had maximized (13) through the direct choice of $\left\{C_{1 t}\right.$, $\left.C_{2 t}\right\}$. This result confirms that, through the choice of taxes and debt, the government can achieve its first-best solution in a decentralized context. This equivalence hinges on the government's ability to set these instruments freely, i.e., that there is one free instrument for each agent at each 
time. We reconsider this assumption below. For now, though, we maintain the assumption that government has the instrument flexibility needed to implement its optimal policy.

Indeed, as this equivalence does not depend on the Cobb-Douglas assumptions, we can consider the direct choice of $\left\{C_{1 t}, C_{2 t}\right\}$ for other assumptions regarding preferences and production. Expression (15) remains the same, although the definition of $r_{t}$ is productionfunction-dependent. For general CES preferences,

$$
U_{t}=\frac{1}{1-\gamma_{1}} C_{1 t}^{1-\gamma_{1}}+\frac{1}{1-\gamma_{2}} E_{t}\left[\beta_{t+1}\left(\frac{C_{2 t+1}}{\beta_{t+1}}\right)^{1-\gamma_{2}}\right]
$$

expression (14) is replaced by:

$$
C_{1 t} A_{t}=\left(\frac{\omega_{t}}{\lambda_{t}}\right)^{\frac{1}{\gamma_{1}}} ; \quad \text { (b) } \quad C_{2 t}=\left(\frac{\omega_{t-1} \beta_{t}}{\lambda_{t}}\right)^{\frac{1}{\gamma_{2}}}
$$

There are a number of interesting points to make concerning the optimal conditions laid out in (15) and either (14) or (17). First, the optimal degree of risk sharing depends on the relative risk aversion of the young and elderly. In (16), $\gamma_{1}$ and $\gamma_{2}$ equal the coefficients of relative risk aversion of the young and old, respectively. If $\gamma_{1}=\gamma_{2}$, then (17) (or (14), for the special case of $\gamma_{1}=\gamma_{2}=1$ ) calls for complete risk sharing. ${ }^{2}$ As discussed by Diamond (1997) and Bohn (1998), this will generally require government instruments to transfer risk between generations. As these authors have noted, the desired degree of risk sharing can be accomplished by adjusting the portfolio of the public pension scheme, for example the share of the Social Security trust fund that is placed in equity rather than debt. But there are many alternative ways to achieve the 
same allocation, and there need be no connection whatsoever between trust fund investment policy and intergenerational risk sharing.

This risk-sharing result holds not only for productivity risks $-C_{1 t} A_{t} / C_{2 t}$ should be independent of $A_{t}$ and $\delta_{t}$ when $\gamma_{1}=\gamma_{2}$ - but also for life-span risk as well: consumption per unit

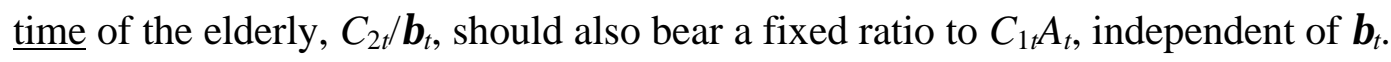

A second result may be observed by comparing conditions (17a) and (17b) for successive periods, using (15):

$$
\left(C_{1 t} A_{t}\right)^{-\gamma_{1}}=E_{t}\left[\beta_{t+1} C_{2 t+1}^{-\gamma_{2}}\left(1+r_{t+1}-\delta_{t+1}\right)\right]
$$

This is precisely the standard Euler equation that prevails in the absence of the capital income tax $T_{2 t+1}$, which implies that capital income taxes should be used to spread risk, but not to distort saving, a familiar result from the dynamic optimal tax literature (e.g. Judd 1989, Chari et al 1994). This is accomplished by taxing only the excess return to capital.

Another point to make regarding the optimal policy involves the evolution of $\lambda_{t}$, the marginal social value of a unit of investment at date $t$. The first-order conditions (17a) and (17b) call for the marginal social value of consumption of young and old to be set equal to this value. Expression (15) also may be viewed as an Euler equation, relating to the shadow price of capital, $\lambda_{t}$. Using (17a) to rewrite (15) in terms of first-period consumption in successive periods (a similar expression holds for second-period consumption), we obtain:

$$
\left(C_{1 t} A_{t}\right)^{-\gamma_{1}}=E_{t}\left[\left(C_{1 t+1} A_{t+1}\right)^{-\gamma_{1}}\left(1+r_{t+1}-\delta_{t+1}\right) \cdot \frac{\omega_{t+1}}{\omega_{t}}\right]
$$


which relates the marginal utility of successive generations' consumption. To understand this result, it is helpful to consider the special case in which $r_{t+1}-\delta_{t+1}$ is known at date $t$. This will be true if $A_{t+1}$ and $\delta_{t+1}$ are known at date $t$. In this case, (19) calls for the marginal utility of firstperiod consumption to follow a random walk, with drift $\left(1+r_{t+1}-\delta_{t+1}\right) \frac{\omega_{t+1}}{\omega_{t}} \approx r_{t+1}-\delta_{t+1}-\eta_{t+1}$, where $\eta_{t+1}=1-\frac{\omega_{t+1}}{\omega_{t}}$ is the government's pure rate of time preference. This finding is reminiscent of Barro's (1979) tax-smoothing result, although here the smoothing of tax burdens associated with the smoothing of consumption derives from the objective of intergenerational equity, not the minimization of deadweight loss for an infinite-horizon household.

Even for this special case of a risk-less return $r_{t+1}-\delta_{t+1}$, consumption itself is not projected to follow a random walk with drift. To see why this is so, consider the simple case in which the drift factor equals zero, so that the optimal policy sets $\left(C_{1 t} A_{t}\right)^{-\gamma_{1}}=E_{t}\left[\left(C_{1 t+1} A_{t+1}\right)^{-\gamma_{1}}\right]$. By Jensen's inequality, it follows that $C_{1 t} A_{t}<E_{t}\left(C_{1 t+1} A_{t+1}\right)$. The logic is straightforward: if we wish to set the expected value of next period's marginal utility to equal a particular level, risk aversion implies that, on average, consumption must exceed its level at this specified marginal utility - the consumption level in the absence of uncertainty. Indeed, the greater the fluctuations in consumption or the degree of relative risk aversion, $\gamma_{1}$, the greater this precautionary saving should be.

This result deserves emphasis: uncertainty about the future should reduce consumption today, and increased uncertainty or risk aversion should reduce consumption more. Greater uncertainty increases the chance of a favorable outcome, in which case the extra saving will prove to have been unnecessary. But it will also increase the chance of an unfavorable outcome, 
and risk aversion will lead us weigh the latter effect more heavily than the former. It does not matter that it is the risk aversion of future generations, because the government's social welfare criterion links the welfare of present generations with those yet unborn. The result also doesn't hinge on whether future generations are expected to be better off than current generations, which should influence the optimal level of saving but not the impact of added risk on that saving.

The equilibrium path of the economy can be described by the solution to two equations in $K$ and $\lambda$, which we obtain using the optimum conditions (15) and (17). For the case of CobbDouglas production, we have:

$$
\begin{aligned}
& \text { (a) } \lambda_{t-1}=E_{t-1}\left[\lambda_{t}\left(1+\alpha K_{t}^{\alpha-1} Z_{t}-\delta_{t}\right)\right] \\
& \text { (b) } K_{t+1}=K_{t}^{\alpha} Z_{t}+\left(1-\delta_{t}\right) K_{t}-\left(\frac{\omega_{t}}{\lambda_{t}}\right)^{\frac{1}{\gamma_{1}}}+\left(\frac{\omega_{t-1} \beta_{t}}{\lambda_{t}}\right)^{\frac{1}{\gamma_{2}}}
\end{aligned}
$$

where we define $Z_{t}=A_{t}^{1-\alpha}$ as the level of total factor productivity. In general, this nonlinear system has no analytical solution. However, we may obtain explicit results for small deviations from a long-run, deterministic steady state by solving a linearized version of (20). In this steady state, the government's pure rate of time preference, $\eta=\frac{\omega_{t}}{\omega_{t+1}}-1$, must be constant, with the rate of return $r^{*}-\delta^{*}$ equal to it. One important limitation of this analysis is that linearization removes elements of risk and risk aversion from consideration. Thus, for simplicity, we set $\gamma_{1}=\gamma_{2}=\gamma$, for which case $\gamma$ equals the inverse of the intertemporal elasticity of substitution. Another apparent limitation is that we implicitly are ruling out permanent trends in the stochastic variables $A, \delta$, and $\beta$, although one can envision deviations of very long duration. 
This linear version of the model has two characteristic roots, one of which is stable $\left(\mu_{1}<\right.$ 1) and the other of which is unstable $\left(\mu_{2}>1\right)$. We obtain the exact solution by imposing two terminal conditions, the fixed value of the initial capital stock and the requirement that the capital stock not explode over time. The result is:

$$
K_{t}=\mu_{1} K_{t-1}+\left(1-\mu_{1}\right) K^{*}+\sum_{s=t}^{\infty} \mu_{2}^{-(s-t+1)} E_{t-1}\left(\Gamma_{s}\right)
$$

where

$$
\Gamma_{s}=Y^{*}\left[\frac{K^{* \alpha}\left(Z_{s-1}-Z_{s}\right)-K^{*}\left(\delta_{s-1}-\delta_{s}\right)}{Y^{*}}-\frac{\frac{1}{\gamma} \omega_{s-1}^{\frac{1}{\gamma}} \beta^{* \frac{1}{\gamma}-1}\left(\beta_{s-1}-\beta_{s}\right)}{\omega_{s}^{\frac{1}{\gamma}}+\left(\omega_{s-1} \beta^{*}\right)^{\frac{1}{\gamma}}}+\frac{1}{\gamma} \cdot \frac{\alpha K^{* \alpha-1}\left(Z_{s}-Z^{*}\right)-\left(\delta_{s}-\delta^{*}\right)}{1+r^{*}-\delta^{*}}\right]
$$

and

$$
Y^{*}=K^{* \alpha}-\delta^{*} K^{*}
$$

is steady-state output.

Each of the terms in brackets in (22) has a straightforward interpretation. The first equals the percent change in the output shock between periods $s-1$ and $s$. The second equals the percent change in "consumption need" induced by the life-span shock between periods $s-1$ and $s$. The last term measures the impact on desired consumption (through the intertemporal elasticity parameter $\gamma$ ) of the percent deviation of the discount factor, $1+r-\delta$, from its long-run value. 
The first two factors call for more resources to be carried into periods when resources are expected to fall or consumption needs increase, while the last factor calls for more saving when the rate of return to capital is higher. However, given that the weighted average of all future expected values of $\Gamma_{s}$ matter, the policy to be followed at date $t$ depends on the anticipated evolution of these shocks.

For example, suppose that total factor productivity follows the first-order process $Z_{t}=\rho Z_{t-1}+(1-\rho) Z^{*}+\varepsilon_{t}$. Then the contribution of productivity shocks to the last term in (21) is:

$$
\left[\frac{1-\rho}{\mu_{2}-(1-\rho)} K^{* \alpha}+\frac{\rho}{\mu_{2}-\rho} \cdot \frac{\alpha K^{* \alpha-1} Y^{*}}{\gamma\left(1+r^{*}-\delta^{*}\right)}\right]\left(Z_{t-1}-Z^{*}\right)
$$

For $\rho$ small (strong mean reversion), the first term matters more; for $\rho$ large (persistent shocks), the second term is more important. However, both terms work in the same direction and the net effect of an increase in $\rho$ is ambiguous. The derivative of the term in (24) with respect to $\rho$ is positive if and only if:

$$
\sqrt{\frac{r^{*}}{\gamma\left(1+r^{*}-\delta^{*}\right)}}>\frac{\mu_{2}-\rho}{\mu_{2}-(1-\rho)}
$$

which, for $\rho \in[0,1]$, is most likely to hold for $\rho=1$, and least likely to hold for $\rho=0$. Indeed, if $\sqrt{\frac{r^{*}}{\gamma\left(1+r^{*}-\delta^{*}\right)}} \in\left(\frac{\mu_{2}-1}{\mu_{2}}, \frac{\mu_{2}}{\mu_{2}-1}\right)$, then there is some critical value of $\rho, \hat{\rho}$, below which the term in (24) decreases with $\rho$ and above which it increases. As $\mu_{2} \rightarrow 1$ (which occurs, for example, as $\alpha \rightarrow 1)$, this interval $\rightarrow(0, \infty)$ and the existence of $\hat{\rho}$ more likely. 
This ambiguity is present because an increase in the duration of a productively shock makes it more valuable to save more, but also less necessary. The relative importance of these efforts depends not only on parameters such as $\gamma$ (a higher value weakening the effect of an increase in $\rho$ ), but also on the value of $\rho$ itself. A similar ambiguity holds with respect to shocks to the rate of depreciation, $\delta$.

On the other hand, the impact of life-span shocks is clear: a positive shock to life span should reduce current capital accumulation. With more consumption needed in the near term, less capital should be accumulated. This result may seem counterintuitive, if one thinks of longer life span as making individuals better off and more able to make transfers to other generations. But the key here is the impact on the marginal value of consumption; with longer life span, a generation must spread its resources over a longer period. We also observe that the more durable this positive shock, the smaller the reduction in capital accumulation - and the greater the decline in consumption - that should occur. This is because future generations are expected to be less able to provide resources for current ones. It seems clear that similar results would hold if the additional value of consumption came from a larger size cohort, that is by an extensive rather than intensive population shock.

How fast and how much investment should respond to these shocks also depends on the values taken by the roots $\left(\mu_{1}, \mu_{2}\right)$. The general expression for these roots is:

$$
\mu_{i}=1+\frac{r^{*}-\delta^{*}+x}{2} \pm \frac{1}{2} \sqrt{\left(r^{*}-\delta^{*}+x\right)^{2}+4 x}
$$

where

$$
x=\frac{Y^{*} \alpha(1-\alpha) K^{* \alpha-2} Z^{*}}{\gamma\left(1+r^{*}-\delta^{*}\right)}=\frac{Y^{*}(1-\alpha) r^{*}}{K^{*} \gamma\left(1+r^{*}-\delta^{*}\right)}
$$


Clearly, $\mu_{1}$ is decreasing in $x$, and $\mu_{2}$ increasing. Thus, for $x$ large (see (21)), investment adjusts quickly ( $\mu_{1}$ is small) and doesn't depend as much on distant future values of the shock term $\Gamma_{s}$ ( $\mu_{2}$ is large). This will be true, for example, for a low value of the risk aversion coefficient, $\gamma$. At the other extreme, as $\gamma \rightarrow \infty, \mu_{1} \rightarrow 1$ and $\mu_{2} \rightarrow\left(1+r^{*}-\delta^{*}\right)$. Higher risk aversion makes adjustment more costly. The same effect occurs as $\alpha \rightarrow 1$, as the marginal product of capital becomes independent of the level of the capital stock. The same effect, it can be shown, also occurs as the elasticity of substitution between capital and labor rises. The intuition is that there is less importance in being at the "wrong" capital stock if deviations in the level of capital have a minimal impact on its marginal productivity.

It is useful to summarize the results thus far. First, as others have noted, government policy should allocate policy risks across each pair of overlapping generations in accordance with their tolerance for risk. This can be accomplished in a variety of ways. Second, policy should adjust at each date to eliminate expected changes in the marginal value of consumption, suitably discounted. Third, with risk aversion and uncertainty, this will generally imply precautionary fiscal policy that sets aside more than what government expects it will need in the future. Fourth, policy should respond differently to productivity shocks and demographic shocks. Like increases in life expectancy, negative productivity shocks require a reduction in investment and a reduction in current consumption, with the latter growing with the expected duration of the shock. However, negative productivity shocks also discourage capital accumulation by making that accumulation less productive, and the net impact on investment of a shock's persistence is no longer clear. Finally, the speed of adjustment should rise with a fall in the degree of risk aversion, or with a decline in the capital share of output or a fall in the elasticity of substitution between capital and labor. 


\section{Limits on Policy Changes}

Thus far, we have considered government policy when there is sufficient instrument flexibility for the government to control consumption directly. In a more realistic setting, this is unlikely to be the case, both because there are more "targets" (such as the consumption levels of different groups within each generation) and fewer "instruments". Once one considers these more realistic cases, it is again necessary to analyze the effects of fiscal instruments explicitly, as consumption levels now must be chosen from a constrained set.

One complication that may arise is that it may not be possible to change government's instruments in every period. This may reflect political difficulties, or implicitly the large fixed costs associated with major policy changes. To be concrete, let us suppose that the tax rates $T_{1}$ and $T_{2}$ cannot be changed in successive periods. Given that each period in an overlapping generations model corresponds to roughly 30 years, this restriction corresponds to the notion that major changes in, say, the Social Security or Medicare system may be possible only once every few decades.

With this restriction, the government's problem now has an additional state variable, say $d_{t}$, which equals 0 if $T_{1 t-1}=T_{1 t-2}$ and $T_{2 t-1}=T_{2 t-2}$ and 1 otherwise. Letting $V_{t}^{0}\left(V_{t}^{1}\right)$ be the government's objective function in period $t$ if $d_{t}=0$ (1), we may express these functions (for the case of Cobb-Douglas preferences) as:

$$
\begin{aligned}
& V_{t}^{0}=\max \left[\omega_{t-1} \beta_{t} \ln C_{2 t}+\omega_{t} \ln \left(C_{1 t} A_{t}\right)+E_{t}\left(V_{t+1}^{1}\right), V_{t}^{1}\right] \\
& V_{t}^{1}=\omega_{t-1} \beta_{t} \ln \bar{C}_{2 t}+\omega_{t} \ln \left(\bar{C}_{1 t} A_{t}\right)+E_{t}\left(V_{t+1}^{0}\right)
\end{aligned}
$$


where $\bar{C}_{i t}$ is the value of $C_{i t}$ chosen when $\left\{T_{1 t}, T_{2 t}\right\}$ equals $\left\{T_{1 t-1}, T_{2 t-1}\right\}$. Note that, with this restriction, the initial level of debt will generally matter. This is evident from inspection of expression (11), for with $T_{2 t}$ fixed, the level of consumption by the elderly $\mathrm{C}_{2 t}$ varies with $B_{t}$.

This problem can only be solved numerically. We use the following approach, starting with some assumed terminal period, say $M$. In period $M$, the world ends and the government must pay off its debt. To do so, it must be able to choose $\left\{T_{1 M}, T_{2 M}\right\}$, which means that it cannot have chosen $\left\{T_{1 M-1}, T_{2 M-1}\right\}$. The choice of $\left\{T_{1 M}, T_{2 M}\right\}$ is made by maximizing the welfare of that period's consumption by young and old, for there is no future. As $\left\{T_{1 M-1}, T_{2 M-1}\right\}$ may not be chosen, this tax vector is set equal to $\left\{T_{1 M-2}, T_{2 M-2}\right\}$. Knowing that it will not choose to vary taxes in period $M-1$, the government faces no cost in varying taxes in period $M-2$ from their previous values; it will vary taxes in period $M-2$ if it can - that is, if it has not varied them in period $M-3$. Thus, for each of periods $M, M-1$, and $M-2$, the government's decision of whether to vary taxes is a trivial one. For periods $M-3$ and earlier, though, the decision must be evaluated using expression (28), comparing the option value of waiting to adjust taxes, $E_{t}\left(V_{t+1}^{0}-V_{t+1}^{1}\right)$, with the current-period cost of doing so, $\omega_{t-1} \beta_{t}\left[\ln C_{2 t}-\ln \bar{C}_{2 t}\right]+\omega_{t}\left[\ln \left(C_{1 t} A_{t}\right)-\ln \left(\bar{C}_{1 t} A_{t}\right)\right]$. As we go back to earlier and earlier periods, we derive the optimal values $\left\{T_{1 t}, T_{2 t}\right\}$ as functions of the state variables, which include the capital stock $K_{t}$ and all relevant information regarding the stochastic variables $A_{t}, \delta_{t}$, and $\beta_{t}$. To obtain infinite-horizon policy rules, we would need to keep going back in time, lengthening the government's planning horizon until these functions converged (i.e., ceased to depend on $t$ ).

To keep the state space manageable, we limit our analysis to cases in which the production terms $A_{t}$ and $\delta_{t}$ are deterministic and constant, normalized to 1 and 0 respectively, and life span, $\beta_{t}$, is governed by a first-order process, $\beta_{t}=\rho \beta_{t-1}+(1-\rho) \beta^{*}+\varepsilon_{t}$, with $\beta^{*}=1$. This 
means that only the current value of $\beta$ enters as a state variable at date $t$. Also, because there is no productivity risk, the before-tax return to capital in period $t$ is known at the beginning of period $t$. Hence, capital and government debt are perfect substitutes and the return to debt, $v_{t}$ (which is needed to calculate $B_{t+1}$ when taxes are fixed in period $t$ ) equals the return to capital, $r_{t}$.

Table 1 presents the results of simulations of this model for different initial values of second-period life span, $\beta$, and the serial correlation of the process governing life span, $\rho$. The innovations of this process, $\varepsilon$, are assumed to be drawn from a uniform distribution over the interval $[-.1, .1]$. Also, the government's discount rate, $r^{*}$, is set equal to 2 and the initial capital stock is set to its steady-state value in the linearized model. ${ }^{3}$ The initial stock of debt is set to zero. Taxes on young and old, $T_{1}$ and $T_{2}$, from the "previous" period, which are state variables because of the government's policy constraints, are both set equal to .1. We assume that policy was not adjusted in the previous period, so that government does have the option of moving in the initial period.

Because the amount of time required for each simulation rises explosively as the government's horizon lengthens, we present results for a four-period horizon, i.e., for period M-3 as defined above. As discussed above, this is the first horizon (from the end) for which the government's decision regarding whether to adjust policy is not a trivial one. Also, given the size of the discount factor and the implicit length of each period, this horizon should be sufficiently long to provide a general picture of the results. We solve the model using a grid search technique. ${ }^{4}$ For each simulation, the table presents the value achieved by the value function at the optimal policy, and the corresponding values of consumption and taxes for young and old and debt and capital carried into the next period. 
For the sake of comparison, we also present simulations for the case in which there are no restrictions on policy changes. The top panel of the table, labeled "unconstrained," presents the results of these simulations, while the simulations for the model with constraints appear in the table's lower panel.

Let us consider first the results for the unconstrained model. As discussed earlier, the government's decision in this case simplifies to a two-step problem: it allocates consumption to each generation in a given period to satisfy the ratio implied by combining expressions (14a) and (14b), and then chooses the capital stock to spread resources over time to satisfy expression (15). This implies that $C_{2} / C_{1}=\left(1+r^{*}\right) \beta$, which equals $3 \beta$ for our assumption that $r^{*}=2$, as the simulations in the top panel confirm approximately. ${ }^{5}$ The unconstrained results are also consistent with the prediction from the linearized model regarding the impact of $\rho$ on the response of consumption to a shock to current life span, $\beta$. Recall that as the shock to $\beta$ is expected to be more permanent ( $\rho$ is large), we can less afford an increase in the current consumption of the elderly. Thus, consumption of the elderly should increase less, and saving should be higher, when $\rho$ is high. Indeed, this is quite evident when we compare the changes in $C_{2}$ as $\beta$ increases for $\rho=.1$ and $\rho=.9$. In fact, saving actually rises with $\beta$ for the $\rho=.9$ case, which may reflect the additional complications of the model over its linearized version, or the fact that our earlier results held for the infinite-horizon case.

Another result worth noting is that, for $\beta=1$, the capital stock is the same when $\rho=.9$ and when $\rho=.1$. To analyze this result, note first that when $\beta_{t}=1, \beta_{t+1}=1+\varepsilon_{t+1}$, so that the distribution of $\beta_{t+1}$ is independent of $\rho$. The distribution of subsequent values of $\beta$ will also have a mean of 1 , but will have greater variance when $\rho=.9$, because shocks will persist. Thus, our finding is that increased future variance has no impact on capital accumulation, a result that 
might seem counterintuitive. It may be shown, however, at least in the two-period version of this model with logarithmic utility, that a simple increase in the variance of $\beta$ is neutral with respect to capital accumulation. In our simulations, the outcome is more complicated because factor prices are also changing with $\beta$, as a result of variations in capital accumulation. Our result suggests that these variations have essentially no net impact.

Turning now to the simulations for the constrained model, we find that in all cases the government chooses to adjust tax policy in the initial period, given the assumed values of $T_{1}$ and $T_{2}$ from the "previous" period (0.1). Because it then cannot adjust policy in the next period, and must adjust policy in the final period, this means that the government's initial policy must stay in place for three periods.

As one would expect, anticipating so little flexibility leads the government to sacrifice current consumption to provide for the future. In percentage terms, the reduction in $C_{1}$ is larger than that in $C_{2}$, perhaps reflecting the fact that the young may be expected to "recover" part of the government's precautionary saving when they are old. The reduction in $C_{2}$ is stronger for higher values of $\rho$ and higher values of $\beta$. We conjecture that the first result derives from the higher variance of future shocks, to which policy may not be able to respond. The second result may be attributable in part to the fact that future generations are, in general, expected to be worse off when the current value of $\beta$ is high. Thus, in each case, the welfare cost of having the "wrong" fiscal policy will be greater (because the errors are greater or their costs are higher), and this leads the government to exact a greater sacrifice from the current elderly.

There may also be a more subtle reason why there is less of a reduction in $C_{2}$ when $\beta$ is small. When $\beta$ is less than 1 , it is expected to rise in the future. With policy set each period, we would then expect to have to raise the consumption of the elderly in the future, presumably by 
reducing their taxes. However, with policy variables constrained at their current values, this adjustment will not be possible. It may be necessary, then, to reduce the taxes on the elderly today, forcing more of the precautionary saving adjustment onto the young. This effect would be most important for low values of $\rho$, when we are more certain that life expectancy will revert to "normal" and rise in the near future. Indeed, it is most observable in the table for the case of $\rho=$ .1 and $\beta=.7$. For this case, the consumption of the elderly does not drop at all between the unconstrained and constrained case - all of the precautionary saving is being forced on the young. This additional effect would be absent, of course, if our transfer to the elderly were fixed not in total value but per unit of time spent in old age, as indeed old-age pension annuities are.

This factor helps explain why the pattern of changes in $C_{1}$ is not monotonic with respect to increases in $\rho$ and $\beta$. Still, taking the changes in $C_{1}$ and $C_{2}$ together, the impact on precautionary saving - the difference in capital between the unconstrained and constrained policy scenarios - is higher and rises more quickly with $\beta$ when $\rho=.9$ than when $\rho=.1$, consistent with the initial intuition given when discussing $C_{2}$.

At the bottom of Table 1, we present estimates of the range of inaction in the policyconstrained version of the model, for the cases of $\beta=1$ and $\rho=.9$ and .1 , respectively. In parentheses are the values of $T_{1}$ and $T_{2}$ that define the boundary of the set over which the government would choose inaction, if the other tax happened to be set equal to its optimal current-period value.

For example, for $\rho=.9$, if the lagged value of $T_{2}$ happened to equal -.075 , its optimal value in the current decision period (in bold in the table), then government would choose inaction for $T_{1} \in[.03, .24]$, bracketing the optimal value (also in bold) of .200. Setting $T_{1}$ at its optimal value of .200, we find an inaction range for $T_{2}$ of [-.20,-.04]. These ranges are quite 
broad relative to those for $\rho=.1{ }^{6}$ This difference suggests that there is much greater value in waiting to adjust policy if next period's information is more "permanent." That is, when $\rho=.9$, the shock in the next period, $M-2$, will also have an important impact on life span in periods $M-1$ and $M$. Thus, being able to adjust policy in period $M-2$ has greater value than it would if the shock in period $M-2$ were more temporary, as it is when $\rho=.1$.

Another interesting pattern in these results is that the optimal values of $T_{1}$ and $T_{2}$ each lie much closer to the upper boundary of their respective inaction ranges than to the lower boundary. We may infer from this that suboptimal current tax rates are much more costly if they are too high than if they are too low. The logic is straightforward: mistakes in the first direction lead to taxes being too high, and consumption too low, for only one set of generations (those currently alive) while mistakes in the other direction lead to taxes being too high, and consumption too low, for a larger number of generations. Being able to spread a given burden over more generations reduces its overall cost, given the concavity of utility and hence the social welfare criterion.

This suggests an apparent paradox, that through its decisions of whether to act, the government will tend to sustain taxes that are too low and cut taxes that are too high, leading to a bias toward taxes that are too low. However, it is important to recall that, if it acts, the government tends to choose taxes that are higher than in the unconstrained case. Thus, taking into account both periods of action and periods of inaction, it does not follow that taxes will be lower, on average, in the constrained world than in the unconstrained world. While our intuition is that taxes will be higher, on average, this is an open question that we hope to resolve in future work. We also hope to explore other questions involving inaction and uncertainty, such as the impact of an expectation that uncertainty will be resolved (i.e., an expected decline in the 
variance of the innovations $\varepsilon$.) In addition, we are exploring how much of the large gap in social welfare between the constrained and unconstrained models can be closed through the use of devices that make political action less necessary, such as indexation of policy variables to the expected lifetime of the elderly.

Table 2 presents the results of the same set of simulations, for the case in which the discount factor, $r^{*}$, is set equal to 1 . For the unconstrained policy simulations, the use of a lower discount rate makes higher capital accumulation optimal. The effects of imposing policy constraints are qualitatively in this table similar to those in Table 1. In particular, the capital stocks under the constrained runs are generally higher than for the comparable unconstrained simulations. However, the increases are much smaller for this lower value of $r^{*}$, presumably because the higher rate of initial capital accumulation leaves greater "margin for error." Indeed, for $\beta=.7$ and $\rho=.1$, the capital stock actually falls when the constraint is imposed. The reason appears to be that discussed above, that the only way to provide a reasonable level of consumption for the longer-lived future elderly is to "overfeed" today's short-lived elderly. Thus, today's young have to bear all (in fact, more than all) of the reduction in consumption induced by policy constraints. As discussed above, this phenomenon would be absent if the policy constraint applied to an old-age annuity rate rather than the total old-age payment.

\section{Conclusions}

One cannot draw universal conclusions from a model as simple as the one used in this paper. However, our results illustrate a number of points relevant to current discussion of longrun policy making. We emphasize two of these points here.

First, it is important to concentrate on fundamental economic effects. The impact of policies ultimately occurs through their impact on distribution and incentives. Thus, we learn 
more by focusing on how policy changes alter distribution and incentives, and not being diverted by superficial distinctions such as whether the policy change takes the form of public pension reform or a shift to a private pension program, or whether the policy change occurs within the pension area or some other part of the government budget.

Second, in itself, the presence of uncertainty about the future offers little apparent justification for waiting to act in response to an anticipated fiscal imbalance. With a risk-averse population, the costs of future outcomes even worse than those expected outweigh the benefits of outcomes better than expected. This suggests not only that action should not be delayed, but further that action should actually be accelerated - that some precautionary saving may be called for, in addition to whatever changes are needed to respond to an expected fiscal imbalance. The added realism of restrictions on the frequency of policy changes alters this result in two offsetting ways. The prospect of being unable to set policy in the future occasions even more precautionary saving today, if the government acts. However, the government may also choose not to exercise its valuable option to set policy and, because the impact of its policies on the elderly cannot be reversed in the future, it is more likely to choose inaction when fiscal tightening is called for. Thus, the optimal policy response over time might best be characterized by great caution in general, but punctuated by occasional periods of apparent irresponsibility. Much research remains to be done on this issue. 


\section{References}

Auerbach, Alan J. and Laurence J. Kotlikoff, 1987, Dynamic Fiscal Policy. Cambridge: Cambridge University Press.

Auerbach, Alan J., Laurence J. Kotlikoff, and Willi Leibfritz, 1999, Generational Accounting Around the World. Chicago: University of Chicago Press, forthcoming.

Barro, Robert J., 1979, “On the Determination of the Public Debt,” Journal of Political Economy, October, 940-71.

Bohn, Henning, 1998, "Risk Sharing in a Stochastic Overlapping Generations Economy," University of California, Santa Barbara, January 1998.

Chari, V.V., Lawrence J. Christiano, and Patrick J. Kehoe, 1994, Optimal Fiscal Policy is a Business Cycle Model," Journal of Political Economy, August, 617-52.

Congressional Budget Office, 1998, The Economic and Budget Outlook: Fiscal Years 19992008, January 29.

Diamond, Peter A., 1997, "Macroeconomic Aspects of Social Security Reform," Brookings Papers on Economic Activity, Fall, 1-66.

Judd, Kenneth, 1989, “Optimal Taxation in Dynamic Stochastic Economies,” Hoover Institution. 


\section{Endnotes}

${ }^{1}$ There is an additional term in the objective function, $-\omega_{t-1} \ln \beta_{t}$, but this doesn't vary with government policy.

${ }^{2}$ Recall that $C_{1 t}$ is measured in efficiency units, so $C_{1 t} A_{t}$ is per capita consumption by the young.

${ }^{3}$ Remember that each period in this life-cycle model represents a generation of perhaps 30 years, so a discount factor of 2 corresponds to a compounded annual discount factor of around 3.7 percent.

${ }^{4}$ We chose this technique after attempts at using derivative-based methods failed to converge. ${ }^{5}$ This relationship holds exactly when we use a high number of potential policy variables in the grid search, but in this case, the computer program can take several days to find the optimal policy.

${ }^{6}$ Indeed, the grid size of .01 being used to estimate the inaction range is really too large for this problem, for the boundaries of the two inaction ranges are at successive points on the grid. 
Table 1. Optimal Policy Rules: Four-Period Horizon

$$
\left(r^{*}=2\right)
$$

\begin{tabular}{lrrrrrr}
\multicolumn{7}{c}{ Unconstrained } \\
$\rho$ & 0.9 & 0.9 & 0.9 & 0.1 & 0.1 & 0.1 \\
$\beta$ & 0.7 & 1 & 1.3 & 0.7 & 1 & 1.3 \\
\hline $\mathrm{V}$ & -2.136 & -2.570 & -3.188 & -2.467 & -2.815 & -3.180 \\
$\mathrm{C}_{1}$ & .149 & .118 & .078 & .140 & .113 & .096 \\
$\mathrm{C}_{2}$ & .304 & .320 & .319 & .280 & .324 & .348 \\
$\mathrm{~K}$ & .058 & .073 & .112 & .091 & .073 & .066 \\
$\mathrm{~T}_{1}$ & .060 & .080 & .136 & .036 & .084 & .116 \\
$\mathrm{~T}_{2}$ & -.104 & -.120 & -.120 & -.080 & -.124 & -.148 \\
Debt & .044 & .040 & -.016 & .044 & .040 & .032
\end{tabular}

\section{Constrained}

\begin{tabular}{lrrrrrr}
$\rho$ & 0.9 & 0.9 & 0.9 & 0.1 & 0.1 & 0.1 \\
$\beta$ & 0.7 & 1 & 1.3 & 0.7 & 1 & 1.3 \\
\hline $\mathrm{V}$ & -2.343 & -3.330 & -4.187 & -2.570 & -2.941 & -3.291 \\
$\mathrm{C}_{1}$ & .111 & .054 & .039 & .089 & .072 & .059 \\
$\mathrm{C}_{2}$ & .287 & .275 & .258 & .280 & .315 & .338 \\
$\mathrm{~K}$ & .116 & .182 & .213 & .141 & .124 & .113 \\
$\mathrm{~T}_{1}$ & .113 & $\mathbf{. 2 0 0}$ & .220 & .133 & $\mathbf{. 1 6 7}$ & .190 \\
$\mathrm{~T}_{2}$ & -.088 & $\mathbf{- . 0 7 5}$ & -.058 & -.080 & $\mathbf{- . 1 1 5}$ & -.138 \\
Debt & -.025 & -.125 & -.162 & -.053 & -.052 & -.052 \\
& & & & & &
\end{tabular}

Inaction Range:

$\mathrm{T}_{1}$

$(.03, .24)$

$(.16, .17)$

$\mathrm{T}_{2}$

$(-.20,-.04)$

$(-.12,-.11)$ 
Table 2. Optimal Policy Rules: Four-Period Horizon

$$
\left(r^{*}=1\right)
$$

\begin{tabular}{lrrrrrr}
\multicolumn{7}{c}{ Unconstrained } \\
$\rho$ & 0.9 & 0.9 & 0.9 & 0.1 & 0.1 & 0.1 \\
$\beta$ & 0.7 & 1 & 1.3 & 0.7 & 1 & 1.3 \\
\hline $\mathrm{V}$ & -2.491 & -2.652 & -2.791 & -2.865 & -3.147 & -3.457 \\
$\mathrm{C}_{1}$ & .258 & .220 & .189 & .235 & .199 & .177 \\
$\mathrm{C}_{2}$ & .358 & .434 & .486 & .330 & .402 & .450 \\
$\mathrm{~K}$ & .160 & .122 & .101 & .211 & .175 & .149 \\
$\mathrm{~T}_{1}$ & -.016 & -.012 & -.004 & -.044 & .020 & .060 \\
$\mathrm{~T}_{2}$ & 0.00 & -.076 & -.128 & .028 & -.044 & -.092 \\
Debt & .016 & .088 & .132 & .050 & .024 & .032
\end{tabular}

\section{Constrained}

\begin{tabular}{lrrrrrr}
$\rho$ & 0.9 & 0.9 & 0.9 & 0.1 & 0.1 & 0.1 \\
$\beta$ & 0.7 & 1 & 1.3 & 0.7 & 1 & 1.3 \\
\hline $\mathrm{V}$ & -2.721 & -3.230 & -3.691 & -2.887 & -3.200 & -3.480 \\
$\mathrm{C}_{1}$ & .244 & .187 & .156 & .219 & .191 & .164 \\
$\mathrm{C}_{2}$ & .351 & .401 & .423 & .354 & .401 & .443 \\
$\mathrm{~K}$ & .181 & .188 & .197 & .203 & .185 & .169 \\
$\mathrm{~T}_{1}$ & -.015 & .035 & .056 & -.015 & .035 & .085 \\
$\mathrm{~T}_{2}$ & .008 & -.043 & -.065 & .004 & -.043 & -.085 \\
Debt & .008 & .008 & .008 & .011 & .008 & .000
\end{tabular}

